\title{
Los nuevos paraísos. Historia y evolución de los parques temáticos *
}

Antonio E. Ten

Arbor CLX, 629 (Mayo 1998), 109-131 pp.

Europa está descubriendo en los últimos años una moda cuyas raíces arraigaron primero en su territorio pero cuyo florecimiento se produjo en los Estados Unidos de Norteamérica. La actual proliferación de parques temáticos y su indudable impacto cultural y económico, los convierte en un fenómeno social digno de estudio. Pese a ello, la bibliografía a ellos dedicada es todavía muy escasa.

El presente artículo describe los origenes de este fenómeno de nuestro tiempo, desde los primeros jardines y exposiciones universales, que pueden considerarse como sus antecesores, hasta los grandes parques de atracciones de principios de este siglo; resalta el carácter educativo no formal que distingue la filosofía de los parques temáticos y destaca el papel de la industria del entretenimiento americana en su popularización.

Por fin, como una de las vías de evolución actual del concepto, se presenta la noción de "parque temático abierto" y se estudian sus posibilidades en los ámbitos del ocio y de la educación del siglo XXI.

El paraíso, para cualquier religión que lo incluya entre sus creencias, es el lugar de la felicidad absoluta. Aún con grandes diferencias sobre

* Este trabajo se ha realizado en el marco del proyecto de investigación COM96-2780 de la CICYT. 
lo que significa "la felicidad", las mayores religiones del planeta han procurado difundir entre sus fieles imágenes de ese fantástico lugar destinado a las personas virtuosas. Para el hinduismo, así, el paraíso representa la fusión con la divinidad, mientras que el budismo lo imagina como el estado supremo y eterno de inmutabilidad y paz. Para el cristianismo, la felicidad suprema es la contemplación de Dios y esa es la única tarea a realizar por los bienaventurados que alcancen su paraíso. El Islam, más gráfico y menos metafísico, ofrece a sus fieles varones, por fin, un paraíso dibujado como un bellísimo jardín en el que ningún placer sensual ni espiritual será negado a quien lo alcance.

Lamentablemente, para llegar a tal lugar, todas estas religiones exigen al ilusionado creyente el desprenderse de los impuros ropajes que le acompañan en esta vida y abandonar el corrupto y tentador mundo material en el que vive. Es decir, morirse.

Pero, pese a los consuelos que para el tránsito han ido acumulando los más brillantes representantes de unas y otras, el común de los mortales no parece haberse conformado a esperar la recompensa a su virtud tras tan desagradablemente reconocido acontecimiento. En la medida de sus posibilidades, todas las culturas han tratado, pues, de ofrecerse anticipos, quizá más prosaicos pero sin duda más reales, de tan etéreo futuro. Así, civilización tras civilización ha dejado en la historia su modelo del paraíso terrenal aquí y ahora.

¿Dónde están los paraísos de la civilización actual? ¿Cuáles son los paraísos terrenales de esa cultura occidentalizada que cada vez se impone más como el modelo mundial de referencia? Existen sin duda paraísos "naturales", tierras vírgenes recónditas, casi todas ya con noticiario de la CNN, cobertura de telefonía móvil, olor a crema bronceadora y máquina dispensadora de Coca-Cola. Existen también recónditos paraísos artificiales para minorías, tan refinados e inclasificables como los gustos particulares de las mismas. Pero ni a unos ni a otros puede aplicárseles con propiedad el calificativo de paraísos. ¡En una sociedad democrática todos deben tener derecho a un paraíso!..., a poca virtud económica que demuestren. Y a juzgar por la atracción que suscitan y el número de visitantes que reciben, por votación popular los paraísos terrenales de nuestra época son sin duda los cada vez más conocidos... "parques temáticos". Este artículo trata de ser una introducción a la historia y a la riqueza conceptual contenida en los actualmente llamados "parques temáticos». 
Los nuevos paraísos. Historia y evolución...

\section{Paraísos a la carta}

La historia de las creaciones humanas organizadas en torno a un tema, a una idea, puede remontarse en el tiempo hasta los mismos orígenes de la civilización. Pero, aunque todo tema puede dar lugar a un parque temático, en la definición de este concepto intervienen elementos que restringen sus contenidos semánticos. En general, puede afirmarse que, en el momento actual, un parque temático es cualquier espacio de ocio y comunicación de masas, construido en torno a un "tema", que sirve de guión y nexo de unión al conjunto de ofertas que este espacio presenta a sus visitantes. Cualquier tema susceptible de interesar a gran cantidad de gente, desarrollado con fines de comunicación - educación en el sentido que veremos-y diversión, puede, pues, convertirse en el "leit motiv» de un parque temático. Quizá el éxito mediático de la película de Steven Spilberg "Parque jurásico", en que los dinosaurios se convierten en el "tema" del parque, ha sido uno de los mejores propagandistas del concepto, pero pueden encontrarse en el mundo parques temáticos en torno a estos famosos animalitos, a Mickey mouse o Bugs Bunny, a alguna famosa batalla con miles de muertos, a las aventuras de un simpático e invencible galo, bajito y con bigotes, a la religión, al sexo... e incluso a los parques temáticos.

De acuerdo con los modelos citados, parecería que el énfasis de este tipo de instalaciones se pone en la idea de "ocio" y, en efecto, este requisito, en una civilización definida como la "civilización del ocio", es sin duda el componente fundamental del éxito de los parques temáticos actuales. En su carácter de paraísos, los parques temáticos son, sin duda y en primer lugar, espacios de diversión. Sin embargo, la realidad que se esconde bajo el concepto es mucho más rica y compleja. Lo que distingue a un parque temático de un circo, feria de pueblo o parque de atracciones, es un interés "educativo" y cultural que lo distingue de esos conceptos próximos, a partir de los cuales ha evolucionado.

En efecto, los parques temáticos actuales pueden considerarse los herederos de dos tradiciones anteriores, de las que han extraído sus mejores ideas ${ }^{1}$. La primera es la de los bien conocidos "parques de atracciones" orientados al puro ocio y que, estables o temporales, aún pueden encontrarse en cualquier ciudad. La segunda tradición es la de las exposiciones "universales", nacionales, regionales o conmemorativas, que siguen también en plena vigencia y que periódicamente se anuncian en los medios de comunicación.

Más o menos cerca de cada uno de estos polos puede situarse cualquiera de los modelos existentes, pero el parquc temático actual 
ha explorado caminos propios que, si bien apuntados en modelos de cada una de las dos tradiciones citadas, han hecho de él un ente nuevo. Como hemos señalado, un parque temático es también una manifestación cultural, más o menos implícita, de unas determinadas sociedades y, más aún, una verdadera propuesta educativa de nuevo género. Detengámonos por un momento en esta idea de educación.

\section{Educar sin escuela}

Todavía, para la mayor parte de la gente, la primera idea que viene a la mente cuando se oye hablar de "educación" es "escuela", que a su vez se representa como un lugar cerrado y aburrido en el que un maestro autoritario exige aprender cosas inútiles. Quizá en muchos casos esta imagen no se aleja demasiado de la realidad, pero, sin duda, los conceptos de educación y escuela, como todos los conceptos realmente vivos, son conceptos dinámicos y en nuestra época ambos han asumido una riqueza conceptual mucho mayor de la que contiene aquel apriorismo. Así, ya es bien reconocido que por "educación", o mejor, por "acción educativa" no puede entenderse sólo el tipo de instrucción que tradicionalmente ha venido impartiéndose en los centros escolares, de cualquier nivel que se consideren.

Pueden distinguirse en este ámbito, al menos, tres contextos o situaciones diferentes que adjetivan, y enriquecen conceptualmente, lo que puede llamarse la "situación educativa" ${ }^{2}$. Junto a la idea de "educación formal", tomada como sinónimo de situación educativa escolar, coexisten situaciones educativas que han dado en llamarse «educación no formal" y "educación informal", cuya importancia en la sociedad actual y para la instrucción de sus ciudadanos, es cada vez más reconocida.

En efecto, en toda situación educativa pueden distinguirse cinco elementos constitutivos: un "contexto" socioeconómico y cultural inmediato, unos "contenidos", un "emisor", un "receptor" o aprendiz y un "espacio» en el que interactúan los elementos anteriores. La mayor o menor relación entre ellos permite individualizar las tres situaciones educativas indicadas.

Así, en la situación educativa formal estos elementos tienden a presentarse, pese a las dificultades que cualquier análisis fino pondría de manifiesto, como voluntaria y explícitamente separados. Un emisor perfectamente definido -el profesor- transmite unos contenidos perfectamente definidos por normativas generales, a unos receptores bien 
clasificados por niveles - los alumnos-, en un espacio singular - la escuela- cuyo diseño y estructura poco tienen que ver, en las sociedades avanzadas y en la mayoría de los casos, con las características del entorno en que se ubica.

La situación educativa no formal tiene una estructura menos rígida. En ella los receptores no tienen por qué estar rígidamente organizados por niveles instruccionales ni por un calendario de actividades reglado. Aún cuando por su propia dinámica tienden a agruparse en grupos homogéneos, se producen importantes interacciones entre estos grupos que enriquecen su estructura. Emisor y contenidos - con objetivos instruccionales perfectamente definidos pero no directamente explicitados- se funden en una única entidad, materializada en diferentes tipos de escenarios, para actuar sobre los receptores, o como ya puede llamárseles más precisamente, "públicos objetivos». Al mismo tiempo, el contexto y el espacio educativo propiamente dicho, aún siendo diferentes, se acercan.

Los parques temáticos, como los museos o las manifestaciones culturales, son buenos ejemplos de situaciones educativas no formales. Un cuidadoso estudio de públicos objetivos, de sus intereses y expectativas, permite definir objetivos alcanzables, que se plasman en propuestas de comunicación - los contenidos diseñados para que actúen de emisores- lo suficientemente atractivas para captar a los colectivos a los que van dirigidas. El espacio educativo se materializa en una escenografía en la que se integran las propuestas de comunicación y que representa contextos reales o imaginarios coherentes con las mismas.

En la situación educativa informal, por fin, contcxto, espacio educativo y emisor se aproximan hasta hacerse prácticamente indistinguibles. Para que se produzca una situación educativa informal se requiere de un diseño de contenidos, tendente a alcanzar unos objetivos de comunicación específicos, culturales, sociales o comerciales, que puedan emitirse por objetos, estructuras o situaciones presentes en la vida cotidiana. El mismo diseño y los objetos que hacen de emisores, seleccionan en primera instancia sus públicos objetivos, que a su vez seleccionan, consciente o inconscientemente, los objetivos de comunicación que más excitan su curiosidad y se sitúan, así, en una situación educativa informal.

Las estructuras familiares, los medios de comunicación, la distribución de unos grandes almacenes, los escaparates de las tiendas de una ciudad, la arquitectura de un barrio, los mecanismos que resuelven necesidades cotidianas, la misma dinámica de relaciones sociales que 
crea un espacio determinado, constituyen, en su relación con los receptores, ejemplos de situaciones educativas informales.

Un parque temático bien concebido, explota intensivamente esta forma de educación en su diseño. Como espacio ideal, en el que desde la construcción de edificios al diseño de las vías de comunicación o la apariencia de los espacios interactivos, están creados específicamente para interaccionar con el visitante, el parque temático es todo un espacio de educación informal. De la especificidad e idoneidad de los objetivos educativos empleados y de los mensajes subliminales que los diferentes contextos emiten, dependerá en último caso la eficacia de su labor educativa.

Pero un parque temático no es sólo un espacio de ocio y comunicación. Un parque temático es también, en una dimensión superior a la de los parques de atracciones o las exposiciones universales, un fenómeno social y económico de primer orden, una aventura infraestructural y económica importante para sus promotores y para el territorio que lo alberga. Como fenómeno de masas, el parque temático va más allá del simple negocio para convertirse en un agente económico y social que modifica sustancialmente su entorno. Como tal, asume una importancia sociológica, administrativa e incluso política que lo configura como uno de los elementos definitorios de la cultura occidental actual.

Bajo la apariencia, pues, de estos espacios, se esconde, como podemos ya intuir, una realidad muy rica. Hay, y puede haber muchos tipos de parques temáticos. Parte del objetivo de este artículo es contribuir también a explorar esta riqueza y, en alguna medida, ampliarla.

Recorramos brevemente algunos de los hitos de la historia de aquellas tradiciones que han contribuido a configurar el actual fenómeno social de los parques temáticos, de los nuevos paraísos para las masas.

\section{Jardines para el pueblo}

Para las culturas más cercanas al mundo occidental, asentadas en terrenos áridos en los que la abundancia de agua, siempre acompañada de vegetación y comida, era uno de los componentes fundamentales de la felicidad, el referente más inmediato del paraíso era sin duda el jardín. En el jardín del Edén, mítica y fertilísima llanura, encerrada entre ríos e imaginada ya por sumerios y acadios, de quienes proviene el nombre, sitúa el libro del Génesis el paraíso de Yaweh, dios de Israel y a su través ha llegado hasta nosotros. Jardines, pues, 
han sido la primera materialización del paraíso que han creado quienes podían concederse tal anticipo de ultraterrenales expectativas.

En parte por el mito y en parte también por la necesidad de proteger tan preciada posesión de más impuras e indignas manos, el paraíso terrenal nace y se mantiene cerrado. En nuestra tradición cercana, el jardín medieval encarna perfectamente este ideal del jardín aislado del mundo exterior, a salvo de peligros y amenazas, protegido incluso por recios muros como el que describe Guillaume de Lorris en su Roman de la rose (ca. 1220) ${ }^{3}$.

Pero el jardín medieval es aún un jardín espiritual, en el que sobrias líneas rectas y plantas escogidas más por su utilidad que por su belleza, contribuyen poco a la excitación de los sentidos. El renacimiento y su exaltación de los goces de la vida terrena, rompe con la monotonía e introduce la curva audaz tras la que se esconde la sorpresa. La humilde acequia cede el paso a la sensual fuente y escondidas entre la vegetación aguardan oscuras grutas y espectrales ruinas que hacen vibrar de emoción los corazones. El jardín barroco italiano crea los modelos en que se mirarán quienes en el siglo XVII aspiran a rendir la naturaleza a los pies del hombre.

Su continuador, el jardín francés imaginado por Le Notre, el creador de Vaux-le Vicomte y Versalles, crea una nueva metafísica en la que el paraíso ya es, indudablemente, de este mundo ${ }^{4}$. Uno y otro pugnan por transformar la naturaleza y "completarla" con fuentes animadas, grutas, máquinas, juegos y artificios: el añorado paraíso se convierte en un parque de atracciones.

$\mathrm{Si}$ al principio los parques son cerrados y reservados a sus afortunados propietarios, nuevas clases comerciales y ciudades libres embellecen sus ocios y sus espacios con paraísos públicos. Bakken, en Klampenborg, al norte de Copenhague, que aún existe como parque público con atracciones y ostenta así el status de patriarca de los parques de atracciones actuales ${ }^{5}$, abre sus puertas al público en 1583. El Prater, de Viena, acoge a sus visitantes desde 1766. Ya en el siglo XIX y en un contexto social y económico diferente, se inaugura, en 1843, el famoso parque de atracciones Tivoli, erigido por el escritor y arquitecto Georg Castersen (1812-59) y que ha dado origen a multitud de parques homónimos por todo el mundo. Junto a éstos, otras muchas ciudades europeas, americanas e incluso japonesas ${ }^{6}$ mejoran su policía urbana y la salud física y mental de su población a lo largo del siglo XIX, promoviendo jardines semejantes.

El jardín paradisíaco se configura así como un ancestro de los parques de atracciones actuales. Si no la felicidad absoluta, cuando 
menos sí proporciona un escape del ambiente cotidiano y sus problemas y un acceso a un mundo de fantasía. Pero esta fantasía, en la segunda mitad del siglo XIX, es una fantasía transida de "nuevas tecnologías". La era del hierro, del vapor y de la electricidad modela un mundo nuevo y una parte de ese mundo se dedica a la diversión. El dominio de la naturaleza y el control de sus fuerzas abrirían a finales del siglo la moda de las atracciones que desde entonces se mantienen como las más populares: las basadas en la velocidad y la fuerza centrífuga. Con la creciente riqueza de las sociedades europea y norteamericana aparece la civilización del ocio y con ella la era dorada de los parques de atracciones.

En Estados Unidos, el país que con mayor ímpetu desarrolló la moda de los parques de atracciones, esta era dorada comenzó tras la guerra civil. El proceso de urbanización de las zonas del noreste, industrialmente más desarrolladas como consecuencia de los esfuerzos de la guerra, dio lugar a la aparición de las primeras compañías de tranvías eléctricos, que deseosas de utilizar su material también los fines de semana, comenzaron a instalar parques de picnic, restaurantes $\mathrm{y}$ atracciones al final de sus líneas. El éxito de dichos parques pronto se extendió por toda América, generando una cultura de ocio cada vez más popular ${ }^{7}$. Junto a los muchos parques de vida efímera, de los 36 grandes parques abiertos en el siglo XIX y que aún continúan operando, 22 son americanos, por 8 ingleses, 2 japoneses, un danés, un sueco, un húngaro y un español, el Parque del Tibidabo, en Barcelona, que abrió sus puertas en $1899^{8}$.

Sin duda los parques más populares en el cambio de siglo, fueron los ubicados en los alrededores de las ciudades de Chicago y Nueva York. En el marco de la exposición universal colombina de 1893, celebrada en Chicago, aparecí la famosa "noria" del ingeniero Ferris. La noria, de 73 metros de diámetro y 9 de anchura, con una capacidad de 1440 personas $^{9}$, se convirtió en un éxito inmediato. Tras el fin de la feria, al año siguiente, el capitán Paul Boynton, recuperando materiales e ideas de la exposición universal, abrí el primer parque de atracciones de una nueva era: las Boynton's Water Chutes, al sur de Chicago, creando el modelo que seguiría hasta la actualidad.

Inspirado por el éxito de Chicago, Boynton extendió la idea a una de las playas más famosas de la costa este, bien conocida por sus hoteles: el 4 de Julio de 1895 abrió sus puertas el área de recreo más conocida de América hasta la llegada de los parques Disney: el parque de Coney Island, al sur de Brooklin, en Nueva York. El establecimiento de Boynton, el famoso "Sea Lion Park", pronto fue acom- 
Los nuevos paraísos. Historia y evolución...

pañado por otros parques de atracciones, de los que los más famosos fueron el "Steeplechase Park" y el "Luna Park", verdaderos mitos del género. A finales del siglo XIX, pues, el modelo estaba firmemente establecido. El siglo XX lo completaría con más y más tecnología al servicio de la diversión pura. Aparecerían los famosos "rides" y "roller coaster", las conocidas "montañas rusas", y las atracciones basadas en los efectos de la aceleración sobre el cuerpo humano. Una nueva manera de divertirse, apoyada en una tecnología tan compleja como invisible, se imponía. Los nuevos paraísos habían nacido.

\section{Exposiciones Universales}

Pero estos primeros grandes parques americanos que consiguieron superar su carácter local y atraer visitantes de áreas alejadas de su lugar de ubicación, tenían una cosa en común: El salto desde lugares de picnic, con atracciones de feria y circo más o menos tradicionales a lugares de emoción, con verdaderas aventuras que ofrecer al precio de unos pocos céntimos, se dio en aquellos en que por otras razones, se reunía una gran cantidad de público, predispuesto a encontrarse con innovaciones de todo tipo. La historia de los parques de atracciones se unía a la de las "exposiciones universales".

Esta historia comienza el 1 de Mayo de 1851, cuando abre sus puertas en Londres la "Gran exposición de los trabajos industriales de todas las naciones", la primera de las exposiciones universales digna de tal nombre. Sus orígenes e historia son bien conocidos ${ }^{10}$. Concebida en una época en que el dominio de la ciencia y de la técnica estaba revolucionando la vida cotidiana de grandes masas de ciudadanos, propiciada por los éxitos ingleses en este ámbito y poco ocultos deseos de propaganda comercial e industrial, la Gran Exposición fue decididamente impulsada por el príncipe Alberto de Sajonia-Coburgo, esposo de la reina Victoria. Formalmente la exposición pretendía recoger bajo un mismo techo los mejores avances tecnológicos e industriales de los países participantes. En la práctica, junto a éstos, la exposición acogió desde los últimos modelos de armas de guerra hasta las mejores obras de los artistas contemporáneos. Por primera vez, las masas encontraban un espacio en el que pasar revista a las innovaciones que estaban cambiando su mundo, de "aprender" muchas cosas sobre un tema, fuera de las escuelas tradicionales.

Si la Gran exposición, que cerró sus puertas el 11 de Octubre del mismo año creó un modelo de exposición temática, también lo creó 
por la singular arquitectura del edificio expresamente construido para albergarla. Obra del ingeniero Joseph Paxton, el Cristal Palace, un gigantesco edificio de acero y cristal de 563 metros de longitud y cerca de 70.000 metros cuadrados de superficie, constituyó un alarde tecnológico que impuso a las exposiciones que la seguirían la obligación de presentar, tanto en sus edificios como en las atracciones anejas, alardes de ingeniería que sirviesen por sí mismos de reclamo publicitario de la exposición en su conjunto. Las exposiciones temáticas se convertirían en verdaderos parques de atracciones.

El éxito popular, comercial y político de la exposición londinense de 1851 , con una media de 42.831 visitantes diarios, fue el mejor acicate para la continuación de la idea. Un grupo de industriales norteamericanos comenzó a promover una nueva "Exposición de industria de todas las naciones", que abriría sus puertas en Nueva York el 14 de Julio de 1853. Otra exposición internacional se inauguraría en Dublín el mismo año y a éstas seguiría, sobre el mismo modelo, la Exposición de Munich de 1854.

Las exposiciones se convirtieron inmediatamente en cuestión de prestigio nacional. Francia organiza en París, en 1855 la «Exposición internacional de productos de la industria", con la participación de 34 naciones. $\mathrm{Si}$ las exposiciones anteriores, siguiendo la moda impuesta por la de Londres de 1851, se celebraron en un recinto espectacular y único, el inevitable Palacio de Cristal, con la de Francia aparece el concepto de "parque de la exposición". Tres pabellones principales, el de la Industria, el de las Máquinas y el de Bellas Artes, se unen entre sí mediante jardines y atracciones diversas. A la exhibición temática destinada a informar y educar, se unen nuevos goces para el cuerpo y el espíritu.

Londres responde a París en 1862, diez años después de la Gran Exposición, con una nueva Exposición Universal. La idea funciona y nuevos países ven en ella una oportunidad de promoción de su cultura y sus productos. En 1863 se celebra la Exposición Universal de Constantinopla, seguida, en 1865, por otras dos "exposiciones universales", las de Oporto, en Portugal, y Dublín, de nuevo. Dos años más tarde abre sus puertas la gran Exposición Universal de París.

La exposición de París de 1867 representa un cambio de escala en este tipo de acontecimientos. La exposición se celebra en un parque gigantesco, con el Gran Coliseo como su edificio más emblemático. En el parque, junto a los espacios de exposiciones en que participan más de cincuenta mil expositores, se ubica, para solaz de los visitantes, un verdadero parque de atracciones. A las razones de prestigio, in- 
Los nuevos paraísos. Historia y evolución...

dustriales y comerciales, que configuran un parque temático dedicado a los avances de la técnica y de la sociedad de consumo, se une definitivamente el objetivo de divertir a sus visitantes. El modelo de París sería copiado en prácticamente todas las exposiciones posteriores ${ }^{11}$.

Desde esta época hasta 1889 , en que, de nuevo en París se celebra una exposición universal para conmemorar el centenario de la revolución, se suceden a ritmo creciente las exposiciones, siempre con el tema de la ciencia y la tecnología como nexo entre las exposiciones industriales, los actos culturales y las atracciones de masas. Cada país quería tener la suya y la opinión pública clamaba por ofrecer esta nueva forma de cultura a los ciudadanos. En el año 1888 llegan a celebrarse jcinco exposiciones universales!, entre ellas la de Barcelona.

La exposición de París de 1889 marca un nuevo hito en el género. En el número 9 de la revista La linterna japonesa, con fecha 22 de Diciembre de 1888, firmando con el seudónimo "Virginia Lebeau», el músico Erik Satie escribía: "Hacia la mitad del año que viene, 1889, habrá una exposición universal en París, pero pasará desapercibida por culpa de la torre Eiffel». En efecto, manteniendo el leit motiv industrial, la exposición de París se convirtió toda entera en un gigantesco parque de atracciones, a mayor gloria del progreso tecnológico. La torre Eiffel, la culminación del parque, lo fue también de la atracción del público, que subía encantado los casi trescientos metros de escalones por el placer para contemplar vistas inéditas de la Tierra. La torre Eiffel significó la definitiva unión del parque de atracciones y la exposición universal. El estudioso de la técnica, el industrial interesado en los avances del progreso, cedía el paso al público curioso, ávido de nuevas experiencias.

Este salto cualitativo se muestra en toda su amplitud en la siguiente gran exposición universal: La Exposición Universal Colombina, que se celebró en Chicago en 1893 y que ya hemos citado en relación con la gigantesca noria del ingeniero Ferris, significó el comienzo de las grandes atracciones mecánicas, explícitamente dedicadas a divertir, que tan populares han seguido siendo hasta la actualidad ${ }^{12}$. Tras la exposición de Chicago, y por efecto ya de avispados empresarios, los parques de atracciones se convirtieron a su vez en templos de la tecnología dedicados a la diversión de las masas. Las siguientes exposiciones universales se convirtieron en verdaderos semilleros de parques de atracciones, que nacían a su lado aprovechando el reclamo de su popularidad, al tiempo que liberaban al cuerpo de las exposiciones de la obligación de proyectar espacios de pura diversión para centrarse 
en los objetivos fundamentales de este tipo de manifestaciones. Otra nueva era comenzaba.

\section{Éxito y declive de los parques de atracciones}

Los siguientes veinticinco años son la era dorada de los parques de atracciones. El éxito de los parques de Coney Island despertó entre los capitalistas e inversores la fiebre de aprovechar el rico filón descubierto. Nuevos y cada vez más arriesgados "riders" y "roller coasters" ${ }^{13}$, pugnaban por satisfacer el deseo de emociones más y más fuertes que demandaban los visitantes. Con Europa inmersa en las catástrofes de la guerra, América, inmersa en una burbuja de prosperidad, se convirtió en un entero paraíso para la industria de los parques de atracciones. En 1919 se contaban alrededor de 1.500 parques en su territorio.

Una verdadera industria de nuevo tipo surgió para atender las demandas de los propietarios por tener la mayor y más emocionante atracción. Ingenieros especialistas se hicieron famosos por sus increíbles construcciones. La historia de los parques de atracciones debe rendir tributo a figuras como la de August John Miller, de Homewood, Illinois, EEUU ${ }^{14}$, inventor de revolucionarias innovaciones en este ámbito y que han sido continuadas por las espectaculares realizaciones actuales. Al mismo tiempo, los accidentes, y su consiguiente publicidad negativa, dieron lugar también a instituciones de control de seguridad, cuyas especificaciones sirvieron en campos muy diversos de la industria. El entramado económico e industrial en torno a los nuevos centros de diversión se retroalimentaba.

Pero la burbuja estalló. América entró en la Gran Depresión en 1929. Las alegrías de los años veinte en todo el mundo terminaron y la industria del ocio demostró cuan ligada estaba a la situación socioeconómica por la que atravesaba la sociedad en que se desarrollaba. En 1935 sobrevivían sólo 400 parques de atracciones ${ }^{15}$. El público comenzó a abandonar los viejos paraísos, que sólo en aquellos lugares que ofrecían formas de ocio complementarias lograban sobrevivir. Hacían falta nuevas ideas y que éstas hicieran vibrar al público al que iban dirigidas.

Un ejemplo paradigmático es el del parque Knott's Berry Farm, en Orange County, California, el primer parque temático americano digno de tal nombre surgido tras la Depresión, que nació casi por casualidad, impulsado por públicos ansiosos de nuevas experiencias. 
Los nuevos paraísos. Historia y evolución...

Knott's Berry Farm tuvo su origen de un puesto de mermeladas de bayas junto a una carretera en Buena Park, en Orange County. Walter Knott, hijo de un granjero, se hizo famoso cultivando un tipo de baya llamado «boysenberry", del nombre de su creador, Rudolph Boysen, quien la obtuvo cruzando moras, frambuesas y frambuesas americanas. Walter Knott abrió un puesto de venta al pie de los campos, dentro de su finca. El inesperado éxito popular de la mermelada, con riadas de coches que se desplazaban los fines de semana a comprar mermelada y a divertirse con los otros compradores, le condujo a la creación de varios restaurantes para atender a los compradores y ofrecerles nuevos servicios. Para singularizarlos se le ocurrió decorarlos con diversos temas del mítico Oeste americano.

De los restaurantes "temáticos", el instinto de Walter Knott lo impulsó a la creación, a partir de 1936, de escenificaciones de la vida del Salvaje Oeste y la vida de sus pioneros. Aparecieron ciudades enteras como Gosth Town, completadas con representaciones de episodios de la historia americana, trenes históricos, recorridos en torno a la historia natural del oeste americano y actividades didácticas para niños y mayores. Tiendas especializadas, restaurantes y espectáculos contribuyeron a crear un mundo ficticio de más de 60 hectáreas visitado por millones de turistas. Knott's Berry Farm continúa atrayendo visitantes actualmente ${ }^{16}$.

La idea mostró sus potencialidades. Tras el paréntesis de la segunda guerra mundial, la bonanza económica reavivó temporalmente los viejos parques de atracciones para, ya en los años cincuenta volver a decaer. La televisión, los coches, la degradación de las ciudades y el crecimiento de suburbios residenciales, junto con un cambio de necesidades de ocio y cultura de las nuevas clases sociales surgidas del desarrollo económico y la universalización de la sociedad de consumo, generaron nuevas demandas que los viejos parques de atracciones ya no podían satisfacer.

\section{El fenómeno Disney}

La industria del entretenimiento y de ella su parte más dinámica, la conectada con el cine y la televisión, consciente de la crisis, comenzó a buscar nuevos modelos que conectasen con las necesidades del público. La palabra mágica fue la fantasía. En 1952 Walt Disney forma la compañía Walt Disney Incorporated, para desarrollar la idea de un "parque familiar" que se llamaría Disneyland ${ }^{17}$. En octubre de 1954, 
la cadena de televisión $\mathrm{ABC}$, asociada con Disney, comienza a emitir el "Disneyland TV Show", con la difusión del documental "The Disneyland Story». Treinta millones de americanos comenzaron a imaginar un nuevo paraíso. Disneyland, se inauguró en Anaheim, California, un 17 de junio de 1955, abriendo sus puertas al público el día siguiente.

Aún cuando muchas de sus ideas se encontraban ya en otros parques y pueden encontrarse algunos precedentes inmediatos, en su imagen global, convenientemente reforzada por una excepcional campaña de marketing y publicidad a través de la televisión, Disneyland era un nuevo concepto de parque de atracciones. En vez de los aparatos típicos y tópicos de los parques anteriores y de espectáculos circenses siempre iguales, unidos por puestos de palomitas y helados, el visitante podía trasladarse, a su elección, a cinco mundos de fantasía diferentes en el espacio y en el tiempo y construidos con todo el realismo posible, personajes de carne y hueso incluidos. Estos espacios, de los que el componente principal era la fantasía del visitante, llevaban los sugerentes nombres de Main Street, U.S.A.; Fantasyland; Tomorrowland, Frontierland y Adventureland, con más de veinte atracciones y espacios de animación separados, organizados temáticamente ${ }^{18}$. Dichos espacios y atracciones, que en los años sucesivos llegaron a ser más de sesenta, convertían al predispuesto espectador, con la colaboración de actores bien entrenados, en un participante más en la aventura ${ }^{19}$.

El éxito fue inmediato y sorprendió a los hasta entonces patrones de la industria de los parques de atracciones que no imaginaban que el público pudiese prescindir de las grandes máquinas y toboganes de la generación anterior. En septiembre de 1955 se alcanzó ya la cifra de un millón de visitantes. Disneyland realizó un excepcional esfuerzo por conectar con las necesidades de nuevos tipos de "públicos objetivos" cuyos intereses habían evolucionado ${ }^{20}$. La idea base, simple tras haber constatado su éxito, consistía simplemente en crear mundos completos de fantasía, en los que cualquier visitante, de cualquier edad, tuviese satisfechas todas sus necesidades, pero con un toque cultural bien dosificado y adecuado a sus posibilidades. El visitante se divertía y además aprendía. Podía hablar de nuevos mundos, recordar episodios de su historia, aprendidos en la escuela, y contar a sus amistades nuevas impresiones e interesantes, aunque superficiales, nuevos conocimientos. La propaganda más eficaz, el "boca-oreja”, extendió rápidamente las excelencias del invento. El nuevo paraíso para los americanos de la postguerra acababa de abrirse y todos querían entrar en él. 
Los nuevos paraísos. Historia y evolución...

Ciertamente, junto con la bondad del producto y su conexión con las expectativas del público, el éxito de Disneyland fue en buena parte motivado por la fama de su creador. Walter Elías Disney (1901-1966), Walt Disney en el mundo de la comunicación, era ya bien conocido de los americanos. Nacido en Chicago, Illinois, el 5 de diciembre de 1901, dibujante precoz, Disney mostró pronto su originalidad creadora. Alistado en la Cruz Roja durante la guerra, su ambulancia llevaba como camuflaje dibujos y tiras cómicas. En 1920 comenzó su carrera como dibujante profesional, trasladándose en 1923 a Hollywood junto con su hermano Roy. Entre ambos comenzaron la producción de dibujos animados para la industrial del cine y en 1928, Walt creó su personaje más universal: Mickie Mouse. El ratón Mickie fue el primer protagonista de una película sonora de dibujos animados. "Steamboat Willie». En 1932 ganó su primer premio de la Academia de las Artes Cinematográficas por la película «Flowers and Trees» ${ }^{21}$.

Con la presentación, en 1937, del primer largometraje de dibujos animados "Blanca Nieves y los siete enanitos», Disney alcanzó la fama mundial. Durante los siguientes cinco años produjo otros clásicos del género: Pinocho, Fantasía, Dumbo y Bambi. La compañía Disney era ya una institución en Estados Unidos y en todo el mundo.

Pero Walt Disney no era sólo un hombre del espectáculo, con gran sentido comercial. Su preocupación pedagógica a través de la diversión lo introdujo muy pronto en el campo de las series de películas-reportaje sobre la vida animal y la conservación de las especies, donde ganó varios premios de la Academia. Pionero también en el mundo de la televisión, sus películas y dibujos animados pasaron a formar parte de la vida diaria de los americanos de los años 50. Cuando Disneyland abrió sus puertas en 1955, el Pato Donald, Dumbo, Mickie Mouse y Minnie recibían a los visitantes. Junto a la sensación de aventura, los americanos tenían también la de sentirse en casa.

\section{La industria de los parques temáticos}

La semilla cayó en tierra abonada. La industria del entretenimiento pronto descubrió las excelencias y los peligros de la nueva fórmula. El 19 de junio de 1960 abrió sus puertas Freedomland, la respuesta a Disneyland en Nueva York: Freedomland, construido con la forma de los Estados Unidos, tenía como tema la historia americana. Freedomland sólo permaneció abierta cuatro años. Falta de un buen marketing y una buena dirección, sin comprender la necesidad de una 
atmósfera cultural, el tema del parque cambió ya en 1962. Se abandonó la historia y el parque se convirtió en un parque de atracciones más, con roller coasters, coches de choque y espectáculos de animación. El 15 de septiembre de 1964 se declaró en quiebra. Su espacio fue ocupado por un gran complejo de apartamentos.

En 1961 abrió sus puertas el primero de la familia de los parques Six Flags: Six Flags over Texas, que pasaría a manos de la Warner Bross y actualmente del conglomerado de empresas Time-Warner, explotando los personajes de dibujos animados de la empresa cinematográfica. En 1964, Universal Studios, recuperando una tradición de cuarenta años atrás, volvió a abrir las puertas de sus estudios de cine en Hollywood a los visitantes, esta vez como un parque temático dedicado al cine. Reconstrucciones de los escenarios de sus películas más famosas, escenificaciones de sus más celebrados pasajes y los escenarios de las películas que se estaban rodando en esos momentos, junto con fugaces visiones de los actores más famosos, servían de atracción principal al parque. Universal Studios Hollywood pronto comenzó a completar su oferta con aparatos de parque de atracciones y la fórmula se mostró también adecuada. Con la misma fórmula, la Universal abrió también Universal Studios Florida. La industria del cine mostraba el camino de la nueva industria del ocio.

El camino, como Disney comprendió bien, parecía aclararse: la formula ideal aprovechaba las ideas de los parques temáticos: fantasía y educación, completadas con la emoción de los nuevos aparatos surgidos para los parques de atracciones. Preocupado por la ecología, que se reflejaba más y más en sus películas y documentales para la televisión, al menos desde 1963, Walt Disney había decidido abrir un nuevo parque en la costa este, en Florida, en el que el entretenimiento fuese también motivo de reflexión sobre la América y el mundo del futuro ${ }^{22}$. Desde principios de 1965 comenzó a dirigir el diseño de un Experimental Prototype Community of Tomorrow (EPCOT). El 15 de noviembre de ese año, Walt y su hermano Roy desvelaron por fin, tras casi dos años de compra de terrenos en secreto, el proyecto del nuevo parque en Orlando, Florida. El proyecto incluiría un parque de atracciones temático, tipo Disneyland y dos ciudades, una tradicional y una futurista, con una inversión inicial de 100 millones de dólares ${ }^{23}$.

Walt Disney murió en diciembre de 1966, pero sus ideas ya habían enraizado. En abril de 1969 comienza la construcción del Magic Kingdom, que se inaugura el 1 de octubre de 1971. Desde 1972 se suceden las aperturas de los complejos que formarán Disney World, hoteles: campos de Golf, villas de vacaciones, la gran reserva zoológica de Trea- 
sure Island, posteriormente llamada Discovery Island, Lake Buenavista Shopping Village, ahora Downtown Disney Marketplace y, por fin, EPCOT. EPCOT, el paradigma de los parques temáticos educativos, comienza a construirse en octubre de 1979 y abre sus puertas el 1 de octubre de 1982, con las áreas que lo convierten en la atracción más espectacular de Disney World: Future World, Horizons, Space Ship, con la famosa Geosphere, The Land, The Living Seas, Universe of Energy, Wonders of Life... y los espacios dedicados a la vida y maravillas naturales y culturales de diversas naciones. El nuevo mundo imaginado por Disney ha conseguido, con EPCOT, acercarse a la filosofía de las exposiciones universales, mientras que sus mundos de fantasía se situaban cada vez más próximos de los parques de atracciones.

La década de los setenta fue sin duda la era de expansion de los parques temáticos en EEUU, como los ochenta lo fueron en el resto del mundo. Magic Mountain, en Santa Clarita Valley, California, abrió el 29 de Mayo de 1971, con buena parte de sus espacios ocupados por aparatos de parque de atracciones. En 1972 se inauguró Opriland, en Nashville, Tennesee, con la música country como eje temático. A Opriland siguieron otros parques musicales como Dollywood, en Pigeon Force, Tennesee, Conway Twitty Entertainement Complex, también en Nashville, Loreta Lynnn's Dude Ranch, en Hurricane Mills, Tennesy o George Jones's Country Music Park, en Colmesneil, Texas. En 1977, los predicadores televisivos Jim y Timmi Faye Bakker, promovieron Heritage USA, en Forth Mill, South Carolina, al que calificaron de "Disneylandia espiritual"... Cualquier tema que pudiese arrastrar un público numeroso tenía ya a principios de los años 80 su parque específico.

En los años 80, la formula se extendió por todo el mundo. Europa y Asia se sumaron a la idea y los parques temáticos comenzaron a florecer fuera del continente americano. Los viejos parques de atracciones realizaron un esfuerzo por reconvertirse en parques temáticos y la frontera entre ambos comenzó a difuminarse. Actualmente, y según cifras de la propia industria, se acercan a novecientos los parques temáticos/de atracciones existentes en Estados Unidos, por doscientos cincuenta en Europa, ciento cuarenta en Centro y Sudamérica, 39 en Próximo Oriente, 36 en Extremo Oriente y seis en Africa.

Por número de visitantes, Tokio Disneyland es el más visitado, con 17 millones de entradas en 1995, seguido por Disneyland con 15 millones de visitantes, por Magic Kingdom con casi 14 millones y Epcot y Disneyland Paris con más de 11 millones. Los cincuenta primeros parques del mundo tienen un rango de visitantes que va de los $17 \mathrm{mi}$ - 
llones al millón en el año $1995^{24}$. Las grandes corporaciones surgidas de la industria cinematográfica, Disney, Metro Goldwin Mayer, Universal Studios, Time Warner, y Paramount, dominan ampliamente el mercado y están orientando de nuevo la industria hacia la filosofía de los parques de atracciones. El éxito de público - de los 25 primeros parques por número de visitantes, 20 pertenecen a las corporaciones citadas - parece mostrar las preferencias de los años noventa. Junto a ellas, continúan floreciendo parques temáticos más específicos, desde los Sea World y los parques acuáticos a los cada vez más abundantes parques históricos y naturales.

$\mathrm{La}$ industria actual parece pues orientarse en dos direcciones principales: la vuelta al entretenimiento puro y la explotación de recursos muy específicos. Si la historia ha mostrado la dependencia de la primera de la situación socioeconómica mundial y el carácter cíclico de esta filosofia, todavía estamos en el primer ciclo de los parques temáticos "puros".

Las enormes y cada vez mayores inversiones necesarias para poner en marcha parques del primer tipo, limitarán necesariamente su expansión y reducirán el mercado a las pocas grandes corporaciones capaces de asumir la aventura económica que representa la construcción y explotación de los mismos. El fracaso de algunos de los parques que se aventuraron en esta línea, muestra los riesgos de la aventura.

Por el contrario, la utilización de recursos naturales y de infraestructuras existentes, en una época en la que el turismo cultural está en alza, puede mantener el explosivo ciclo ascendente de los parques temáticos puros. Sin duda, ésta es una de las líneas de estudio prospectivo que pueden tener repercusión sobre la sociedad del ocio que se avizora en el siglo XXI.

\section{Una nueva generacion de parques tematicos. los "parques temáticos abiertos"}

Abstrayendo lo esencial de los ejemplos existentes, un parque temático es, pues, una propuesta de comunicación y ocio, simple y fácil de captar por sus públicos objetivos potenciales, en torno a uno o varios temas. Dicha propuesta se concreta en una serie de infraestructuras e instalaciones en las que se materializa el "tema" del parque y que se presumen atractivas para sus públicos objetivos. I a mayor o menor explicitación del proyecto didáctico de base y el balance entre ocio y 
Los nuevos paraísos. Historia y evolución...

educación, establecen una gradación de los parques temáticos, que va desde los parques de atracciones puros a los museos tradicionales.

Los parques temáticos que hasta ahora ha construido la iniciativa privada son, necesariamente espacios bien cerrados y acotados, de carácter permanente, en los que es fácil el control de visitantes y el cobro de derechos de entrada por el acceso a sus instalaciones. Como aventuras económicas a gran escala, su viabilidad sólo es posible si pueden mantener durante largo tiempo, un flujo considerable de usuarios y si se consigue que, además, los visitantes consuman mayoritariamente los servicios complementarios que el parque pone a su disposición, especialmente en el campo de la restauración y la oferta de objetos propios.

Los grandes parques cerrados, la experiencia lo demuestra, "agotan" pronto el territorio y el mercado disponibles, distribuyéndose, necesariamente por zonas de influencia nacionales y en muchos casos internacionales e incluso continentales. Su número está limitado, más que por sus contenidos temáticos posibles, por la considerable inversión a realizar y por el potencial demográfico de su área de influencia. Los parques temáticos menores existentes hasta ahora, o bien explotan recursos de temporada, como los parques acuáticos, o bien están ligados a características físicas o históricas que hacen popular su emplazamiento, o bien coinciden con singularidades culturales de la zona en que se ubican. En cualquier caso, hasta ahora, la gran mayoría de los parques existentes se han enfocado prioritariamente como estructuras empresariales cuya viabilidad económica pasa por obtener la amortización de las inversiones realizadas, además de lograr beneficios de explotación semejantes o superiores a los de otras alternativas de inversión.

¿Existen otras vías por explorar en el mundo de los parques temáticos? Conocida a grandes rasgos la historia y la filosofía de los parques temáticos, su indudable éxito en nuestra sociedad y su utilidad como espacios de comunicación, sugiere que el concepto y las técnicas de marketing que en ellos se emplean, se extiendan a áreas de actividad humana organizadas naturalmente en torno a un "tema" y susceptibles, o necesitadas, de "comunicar" su existencia $\mathrm{y}$ actividades.

Una de las más prometedoras extensiones, entre las que pueden entreverse en este momento, es la que se encierra en la idea generatriz de lo que pueden llamarse "parques temáticos abiertos".

En esencia, un parque temático abierto es una propuesta de comunicación, dirigida a públicos objetivos específicos, que utiliza, unién- 
dolas mediante una o varias líneas temáticas, edificios e instalaciones ya existentes, dedicadas a fines diversos dentro de un contexto común y no concebidas, en principio para este fin. Dicho contexto es, naturalmente, el que proporciona las líneas temáticas sobre las que construir la propuesta de comunicación.

Adaptar así mundos reales como parques temáticos, contemplándolos como objetivos de comunicación y de educación a través del ocio, en vez de construir mundos ideales, permite abaratar drásticamente los costes, sobre todo teniendo en cuenta que las costosas infraestructuras necesarias en un parque cerrado, existen ya a disposición de todos en el área en que se ubicará el parque temático abierto. Además, al no tener que amortizar infraestructuras, los parques temáticos abiertos pueden ser permanentes o temporales y aprovechar coyunturas específicas para potenciar así sus objetivos de comunicación. Las necesidades de financiación son, por tanto, mucho más reducidas y ello se traduce en unas menores exigencias de rentabilidad económica y en una mayor flexibilidad de diseño.

Implícitamente, dichos parques temáticos ya existen. Es más, contemplados desde esta perspectiva son abundantísimos: Playas de moda, cascos antiguos y barrios singulares de ciudades historicas, estaciones de esquí, espacios naturales, grandes instituciones o empresas que admiten visitantes, deseosas de mejorar su imagen... han ido convirtiéndose, intuitivamente, en verdaderos "parques temáticos abiertos", en torno al tema que hacia ellos atrae a sus visitantes. Al socaire del tema de turno aparecen servicios, espacios de ocio, tiendas especializadas... que se van añadiendo más o menos anárquicamente. Salvo en contados casos, sin embargo, la inexistencia de una filosofia de comunicación y servicios integrada, no les ha permitido aprovechar el cúmulo de posibilidades que su atractivo natural ofrecía.

Así pues, para abrir más este cúmulo de posibilidades, el paso siguiente es ya inmediato:

- Si a estos embrionarios parques temáticos se les añade una propuesta de comunicación simple y fácil de publicitar, orientada a los públicos objetivos definidos en el proyecto de comunicación, de acuerdo con los objetivos que para el parque se establezcan.

- Si para todos estos tipos de públicos se desarrolla un proyecto de educación no formal e informal que desarrolle adecuadamente los objetivos educativos elegidos y establezca los medios necesarios para alcanzarlos.

- Si del conjunto de actividades "naturales" del candidato a parque temático abierto se extraen las más susceptibles de 
conjugar ocio y educación y se completan éstas con espacios destinados a reforzar los mensajes definidos en el proyecto de comunicación...

...una ciudad, una institución, una empresa... se convierte en un verdadero parque temático.

Naturalmente, la realidad no es tan simple. La pérdida de la «atmósfera" que los parques temáticos comerciales crean fácilmente en su interior, debe compensarse con una redefinición de las estrategias de marketing y publicidad y con una planificación de actividades y gestión de flujos de visitantes más específicas. En un parque temático abierto, con propuestas de comunicación dispersas espacial y temporalmente, el visitante necesita sentirse más apoyado en sus posibles recorridos que en un parque cerrado. Problemas como la información, la señalización, la circulación de visitantes entre espacios de comunicación más o menos alejados entre sí, la confusión entre mensajes del parque y de su contexto, las reservas a los espacios con limitación de capacidad, la atención a particulares y grupos... requieren de órganos de gestión especializados.

La formación de estos órganos de gestión configura, sin duda, un reto para el candidato a parque temático abierto y es un punto crucial para su éxito. Afortunadamente, la historia de los parques cerrados y de sus progenitores, los parques de atracciones y las exposiciones temáticas, proporciona valiosas lecciones. Asimismo, las experiencias, positivas y negativas, que pueden obtenerse del estudio de manifestaciones asimilables, como grandes conmemoraciones y aniversarios, hitos culturales globales como capitalidades culturales, eventos deportivos como olimpiadas y campeonatos internacionales, celebraciones festivas masivas... proporcionan al atento estudioso algunas de las claves para alcanzar adecuadamente los objetivos propuestos

La onda actual de los grandes parques temáticos se orienta prioritariamente hacia el ocio y sin duda la moda conocerá reflujos como los del pasado. Los parques temáticos menores explotan expectativas puntuales de sus públicos potenciales y se mantendrán mientras dichas expectativas se conserven. La cultura del ocio y la comunicación hacia la que se dirige la sociedad occidental en el siglo XXI valorizará sin duda los parques temáticos abiertos cuya flexibilidad y economía los convertirán en potentes armas para instituciones y empresas que quieran conectar mejor con sus potenciales visitantes y consumidores y cuyas expectativas de rentabilidad vayan más allá del beneficio económico inmediato. 


\section{Notas}

1 SorkIN, M. (1992): See you in Disneyland. En: SoRkIN, M. (Ed.): Variations on a Theme Park. The New American City and the End of Public Space. Hill and Wang, N. York.

2 Rrvas, F. (1997): El proceso de enseñanza /aprendizaje en la situación educativa. Ariel, Barcelona, pp. 31, 62-70.

3 ElenA, Alberto (1986): Científicos, filósofos y jardineros: la restauración del paraíso terrenal. En: ACTAS del III congreso de la Sociedad Española de Historia de las Ciencias. Ed. Guipuzcoana, San Sebastián, Tomo I, pp. 265-274.

4 WeIsS, Allen S. (1995): Mirrors of infinity. The French Formal Garden and 17th-century Metaphysics. Princeton Architectural Press, Princeton.

5 National Amusement Park Historical Association (1997): The Amusement Park Industry. A very Brief History. http://www.sgi.net/napha/history.html.

6 El parque Hanayashiki, de Tokio, abre sus puertas en 1853, en un contexto de apertura de Japón a las ideas occidentales. NATIONAL AMUSEMENT PARK HISTORICAL AssoCiATION (1997): Industry FAQ. http//www.napha.org/faq.html.

7 ADAmS. J.A. (1991): The American Amusement Park Industry. A History of Technology and Thrills. $\mathrm{s} / \mathrm{h}$, Twaine Publishers.

8 National Amusement PaRK Historical Association (1997): Industry FAQ. http://www.napha.org/faq.html.

9 Calvo. Luís (1992): Exposiciones universales. Labor, Barcelona, p. 69.

10 ALwood, J. (1977): The Great Exhibitions. London, Studio Vista; GIBBS H.C (1981) The Great Exhibition of 1851. London; HMSO; LIVRE des expositions universelles 1851-1929 (1983). Union centrale des arts decoratifs, Paris.

11 Calvo, Luís (1992): Exposiciones universales. Labor, Barcelona, p. 55.

12 McCullogh, E. (1976): World's Fair Midways. Arno Press, N. York, Desde esta época, la palabra inglesa «midway* asume también un significado especializado como la avenida central de un parque de atracciones, a la que se asoman las atracciones más espectaculares.

13 El popular «Dragon Kahn* del parque español «Port Aventura*, en Salou,Tarragona, es un ejemplo cercano de las pasiones que tales atracciones despertaban y continúan despertando en el público.

14 Una interesante biografía de John A.Miller, comc firmaba sus obras, junto con una historia de estas atracciones, puede encontrarse en la dirección http://www.fmcg.com/jmiller.

15 National Amusement Park Historical Association (1997): The Amusement Park Industry. A very Brief History. http://www.sgi.net/napha/history.html.

16 Amplia información de sus contenidos, programas pedagógicos, atracciones y actividades de animación puede encontrarse en la dirección internet http://www.knots.com/homepage/homepage.htm.

17 Polsson, K. (1995-6): Chronology of Events in the History of Disney. http:// www.islandnet.com/ kpolsson/disn1950.htm.

18 Las atracciones de cada uno de los mundos dan buena idea de su contenido temático. Como muchas de ellas ya han cambiado o desaparecido, quizá sea interesante para el lector recordar su contenido, con los mismos nombres que les dio su creador. En Main Street U.S.A se encontraban las siguientes: Disneyland Rairoad, Horse-drawn Streetcars, Horse-drawn Fire Wagon, Main Street Cinema, Horse -drawn Surreys y 
Los nuevos paraísos. Historia y evolución...

la Main Street Shooting Gallery. Fantasyland estaba compuesta por los siguientes espacios: King Arthur Carrousel, Peter Pan Flight, Mad Tea Party, Mr, Toad's Wild Ride, Canal Boats of the World, Snow Withe's Adventures, Casey Jr. Circus Train, Dumbo Flying Elephant y el Mickey Mouse Club Theatre. Tomorrowland incluía Autopia, Circarama (con la "A Tour of the West", proyectada sobre una pantalla de 360 grados), Space Station X-1, Monsanto Hall of Chemistry, Phantom Boats, Rocket to the Moon, Flight to the Moon, 20.000 Leagues Under the Sea y el Flight Circle. Frontierland disponía de las siguientes atracciones: Stage coach, Mules Pack, Mules though Nature's Wonderland, Mark Twain's Steamboat, Golden Horseshoe Revue, Conestoga Wagons y los Mike Fink Keel Boats. Adventureland, por fin, escenificaba un crucero por la jungla. En los años siguientes fueron retirándose las atracciones menos apreciadas e introduciéndose otras nuevas. Una información sobre estos cambios puede encontrarse en: FORTY Years of Disney land Adventures Fact Sheet (1997) http:// www.disney.com/disneyland/index.html.

19 Koenig, D. (1994): Mouse Tales (A Behind-the-Ears Look at Disneyland).Bonaventure Press, Irvine.

20 Una exhaustiva bibliografía sobre el fenómeno Disney, puede encontrarse, por ejemplo en http://www.islandnet.com/ -kpolson/disnehis.db2.

21 WALT Disney Biography (1997): http:// www.disney.com/disneyland/index.html.

22 FJellman, S.M. (1992): Vinyl Leaves. Walt Disney World and America. Westview Press, Boulder. world.

${ }^{23}$ WALT Disney World Trough The Decades (1997): http://www.disney.com/disney-

24 Ultimate Guide Productions. (1997): North American Theme/Amusement Park Attendances. http://home.earthlink.net/ croooow. 